\title{
Preparation of CdSe/RGO-GO composites with the high performance of adsorption and degradation
}

\author{
J.C. Sun ${ }^{1,2}$, Z. C. Bai ${ }^{1}$, Z. L. Huang ${ }^{3}$, Z. P. Zhang ${ }^{\dagger, 1}$ \\ †zpzhang@gzu.edu.cn
}

\begin{abstract}
${ }^{1}$ College of Big Data and Information Engineering, Guizhou University, Guiyang City, 550025, P. R. China
${ }^{2}$ School of Computer and Information Engineering, Anhui Polytechnic University, Wuhu City, 241000, P. R. China

${ }^{3}$ Guizhou Key Laboratory of Optoelectronic Technology and Application, Guizhou University, Guiyang, 550025, P. R. China
\end{abstract}

Nowadays, dyes are usually chemically stable, can not be degraded naturally within a short time, and easy to migrate along with water, which is the main source to influence the health of human beings and to destroy the ecosystem. Based on that, in this work a high-performance photocatalyst was prepared successfully by an organic synthesis method. The obtained photocatalyst contained numerous nanoscale heterojunctions, which consisted of CdSe nanoparticles scattered on the partially reduced graphene oxide (named as CdSe/RGO-GO). The samples were characterized by photoluminescence spectra (PL), transmission electron microscopy (TEM), and ultraviolet and visible spectrophotometry (UV-vis). The photocatalytic activity was evaluated by the degradation of organic dyes Rhodamine $B(R h B)$ aqueous solution under irradiation of visible light and no light. Results show that the degradation efficiency of nanocomposites was $84.4 \%$ in the first 10 minutes under darkness. After 50 minutes of visible light irradiation, the degradation efficiency was $94 \%$. The high degradation efficiency of photocatalysts attributes to the synergistic effect of graphene oxide adsorption and heterojunctions catalysis. CdSe/RGO-GO photocatalyst reported in this paper has a series of advantages, such as pollutionfree, recyclability, stability, and insolubility in water. The preparation of CdSe/RGO-GO composites has potential applications in curbing pollution.

Keywords: photocatalyst, CdSe, graphene oxide (GO), reduced graphene oxide (RGO), nanometer heterojunctions.

УДК: 544.22

\section{Подготовка композитов CdSe/RGO-GO с высокими показателями адсорбции и деградации}

\author{
Сун Дж. Ч., ${ }^{1,2}$, Бай Ж.Ч. ${ }^{1}$, Хуанг Ж. Л. ${ }^{3}$, Жанг Ж. П. ${ }^{\dagger}$ \\ ${ }^{1}$ Колледж больших данных и инженерной информации, Университет Гуйчжоу, Гуйян, 550025, Китай \\ ${ }^{2}$ Школа компьютерной и информационной инженерии, Политехнический университет Аньхой, Уху, 241000, Китай \\ ${ }^{3}$ Гуйчжоуская ключевая лаборатория оптоэлектронных технологий и приложений, Университет Гуйчжоу,
}

Гуйян, 550025, Китай

В настоящее время красители, как правило, химически стабильны, не могут разлагаться естественным путем в течение короткого времени и их легко переносить вместе с водой, которая является основным источником воздействия на здоровье людей и разрушения экосистемы. Исходя из этого, в данной работе был успешно изготовлен высокопроизводительный фотокатализатор методом органического синтеза. Полученный фотокатализатор содержал многочисленные наноразмерные гетеропереходы, которые состояли из наночастиц CdSe, рассеянных по частично восстановленному оксиду графена (CdSe/RGO-GO). Образцы были изучены с помощью спектров фотолюминесценции (ФЛ), просвечивающей электронной микроскопии (ТЭМ) и ультрафиолетовой и видимой спектрофотометрии (УФ-визуализация). Фотокаталитическую активность оценивали по разложению органических красителей водным раствором родамина $\mathrm{B}(\mathrm{RhB})$ при облучении видимым светом и без света. Результаты показывают, что эффективность разложения нанокомпозитов составляла $84.4 \%$ в первые 10 минут в темноте. 
После 50 минут облучения видимым светом эффективность разложения составила 94\%. Высокая эффективность деградации фотокатализаторов объясняется синергетическим эффектом адсорбции оксида графена и катализа гетеропереходов. Фотокатализатор CdSe/RGO-GO, о котором сообщается в этой статье, обладает рядом преимуществ, таких как отсутствие загрязнений, возможность вторичной переработки, стабильность и нерастворимость в воде. Подготовка композитов CdSe/RGO-GO имеет потенциальные возможности для предотвращения загрязнения.

Ключевые слова: фотокатализатор, CdSe, оксид графена (GO), восстановленный оксид графена (RGO), нанометровые гетеропереходы.

\section{Introduction}

Environmental pollution has become a serious worldwide issue threatening the ecological condition and health of human beings [1,2], and dyes are one of the most important kinds of pollutants. Various physical and chemical methods have been developed to deal with these dye pollutants and achieved great success $[3,4]$. However, these methods still suffer from high-cost, enormous energy consumption, and complex procedures. Now, photocatalytic decomposition by solar energy has been deemed as an alternative method to solve dye pollution because it can conquer the drawbacks of traditional methodologies [5].

Nanoscale semiconductor materials are a promising photocatalysts [6,7]. However, they still cannot meet the critical requirements of practical applications, which is mainly constrained by their low decomposing efficiency for dyes. Therefore, improving the performance of the nanomaterial photocatalysts is necessary. Constructing heterojunction is an important method in the semiconductor field. Photocatalysts with nanoscale heterojunctions have the advantages of both nanomaterials and heterojunctions, which have been developed rapidly in recent years [8]. Due to the special energy band structure of heterojunctions photocatalysts after being carefully engineered, the recombination of photogenerated excitons can be inhibited, which can substantially improve the internal quantum efficiency. It's worth noting that the band gap is one of the most important criteria to design highperformance photocatalysts. Semiconductors with large band gaps can not efficiently use the broad solar spectrum, but only a little portion of short wavelengths $[9,10]$. Fortunately, CdSe has an appropriate band gap in the range of 1.65 to $1.8 \mathrm{eV}$, covering the wide wavelength range of the solar spectrum [11]. Therefore, the nano-heterojunctions with the CdSe can obtain high-performance photocatalysts.

Graphene, a flat monolayer of carbon atoms, has the unique characteristics of electron transportation and charge mobility $[12,13]$. It enables fast transport of the catalytically generated electrons by the semiconductor materials, promoting the separation of photo-generated excitons. These active electrons and holes can be used to decompose dyes. Graphene oxide (GO) is the graphene functionalized with oxygen-containing groups, which can adsorb organic pollutants such as Rhodamine and heavy metals [14]. The large surface area of graphene and graphene oxide facilitates the dispersion of nanomaterials onto their surfaces. Therefore, both graphene and graphene oxide have been adopted in photocatalytic fields [15].

In this work, a high-performance CdSe/RGO-GO photocatalysts, composed of CdSe nanoparticles scattering onto the partially reduced GO (RGO) was prepared by a simple organic synthesis method. The preparation process is simple, low-cost, and free of secondary contamination, as well as the outstanding photocatalytic performance. The preparation method has promising applications in the remediation of environmental pollution.

\section{Experiment}

\subsection{Materials}

GO was fabricated by using Hummer's-Offeman method. Ethanol $\left(\mathrm{CH}_{3} \mathrm{CH}_{2} \mathrm{OH}, \mathrm{AR}\right.$, density $\left.0.789-0.791 \mathrm{~g} / \mathrm{mL}\right)$ and methanol $\left(\mathrm{CH}_{3} \mathrm{OH}, \mathrm{AR}\right.$, density $0.791-0.793 \mathrm{~g} / \mathrm{mL}$ ) were purchased from Tianjin Fuyu Fine Chemical Co. Ltd., China. Acetone $\left(\mathrm{CH}_{3} \mathrm{COCH}_{3}, \mathrm{AR}\right.$, density $\left.0.790 \mathrm{~g} / \mathrm{mL}\right)$ was bought from Chongqing Chuandong Chemical Group Co.Ltd., China. The selenium powder (Se, AR) was obtained from Tianjin Jinbei Fine Chemical Co. Ltd., China. The cadmium oxide powder (CdO, AR) was purchased from Tianjin Comio Chemical Reagents Co.Ltd., China. The liquid paraffin was supplied by Jining Baichuan Chemical Co.Ltd., China. The oleic acid $\left(\mathrm{C}_{18} \mathrm{H}_{34} \mathrm{O}_{2}, \mathrm{AR}\right.$, density $\left.0.889-0.895 \mathrm{~g} / \mathrm{mL}\right)$ was purchased from Guangdong fine chemical products Engineering technology research and development center, China. Rhodamine B (RhB, AR, $\geq 99 \%$ ) was obtained from the Tianjin Comio chemical reagents development center, China. All the chemicals were used as received without further purifications. Deionized water was used throughout the experiment.

\subsection{Synthesis of CdSe/RGO-GO photocatalysts}

\subsubsection{Processing of graphene oxide}

A certain quality of GO was milled into fine powder in an agate mortar and put into a beaker, which was then add a proper amount of deionized water (prepared into $1 \mathrm{mg} / \mathrm{mL}$ GO aqueous solution). Following that, the beaker was put into the ultrasonic cleaner for two hours to obtain uniformly dispersed GO aqueous solution. Then the dispersion was irradiated by an ultraviolet (UV) lamp (xenon-mercury lamp, model L8878-02) with a power of $200 \mathrm{~W}$ for 6 hours to reduce GO into RGO [10]. At this time, the partially reduced GO solution was obtained and dried to be powder. Then, as-prepared $0.005 \mathrm{~g}$ reduced GO powder was put into $10 \mathrm{~mL}$ anhydrous ethanol to disperse by ultrasound for $30 \mathrm{~min}$. Finally, well-dispersed partially reduced GO ethanol dispersion with a weight concentration of 0.063 wt.\% was obtained. 


\subsubsection{Synthetic method of CdSe/RGO-GO Nano- Heterojunction}

Two three-mouth flasks named as flask 1 and flask 2 were washed thoroughly by using deionized water. Firstly, $2 \mathrm{~mL}$ of oleic acid and $8 \mathrm{~mL}$ of liquid paraffin plus a magnetic rotor were put into the flask 1 . After that, the flask was sealed and placed into an oil pot full of simethicone. Then the pot was heated to $190^{\circ} \mathrm{C}$ under magnetic stirring and keep constant temperature. At the same time, $20 \mathrm{~mL}$ of paraffin and a magnetic rotor were put into the flask 2 , then sealed and placed into an oil pot full of simethicone to heat to $200^{\circ} \mathrm{C}$ and keep the constant temperature under magnetic stirring. When the two flasks were kept constant temperature, $0.26 \mathrm{~g}$ $\mathrm{CdO}$ powder was added into the flask $1,0.032 \mathrm{~g}$ Se powder and $1.2 \mathrm{~mL}$ of as-prepared $0.063 \mathrm{wt} . \%$ RGO absolute ethanol dispersion solution was put into flask 2 . The two flasks were magnetic stirred and heated continuously. After 1 hour, the flask 1 stop heating and magnetic stirring. Then $5 \mathrm{~mL}$ solution taken from the flask 1 was put into the flask 2, keep flask 2 at $200^{\circ} \mathrm{C}$ for $25 \mathrm{~min}$. Next, a mixture of $46.6 \mathrm{~mL}$ of methanol and $9.4 \mathrm{~mL}$ of acetone was put into a beaker as the quencher for temperature quenching. After the solution cooled down to room temperature, the supernatant liquid was removed. The left bottom solution was centrifuged 3 times, the condition set as 5000, 8000, and $5000 \mathrm{rpm}$ respectively for $5 \mathrm{~min}$. Finally, the oil phase CdSe/RGO nano heterojunctions were obtained. The synthesized nanometer heterojunctions material is named CdSe/RGO-GO.

\subsection{Characterizations}

The morphology and the fine structure of the synthesized samples were characterized by transmission electron microscopy (TEM, JEOL, JEM-2100F, Japan). The absorption spectrum was measured using an ultraviolet (UV)-visible absorption spectrophotometer (UV-2600A, China). The photoluminescence (PL) spectrum was studied by a photoluminescence spectrometer (Ocean Optics, QE6500).

\subsection{Evaluation of the photocatalytic activity}

\subsubsection{Quantitative analysis}

In the experiment, the CdSe/RGO-GO nano heterojunctions were synthesized with $0.6,0.8,1.2,1.4,1.6$ and $1.8 \mathrm{~mL}$ RGO absolute ethanol solution respectively. As shown in Fig. 1, the red shift of photoluminescence fluorescence peaks indicates that the number of CdSe quantum dots (QDs) and heterojunctions has increased, and the catalytic performance is strengthened. It is known that the intensity of PL peaks is higher, the number of recombined photo-generated electron-hole pairs is greater. The lifetime of the photo-generated carriers is shorter, and the ordered structure of graphene is more stable [16]. Therefore, the fluorescence peak of pure CdSe quantum dots is the strongest, while the fluorescence peak of nano-heterojunctions synthesized by $1.2 \mathrm{~mL}$ is the weakest, which is the strongest catalytic performance among all samples. Based on the above analysis, CdSe/RGO-GO nano-heterojunctions synthesized by $1.2 \mathrm{~mL}$ is chosen to degrade $\mathrm{RhB}$.

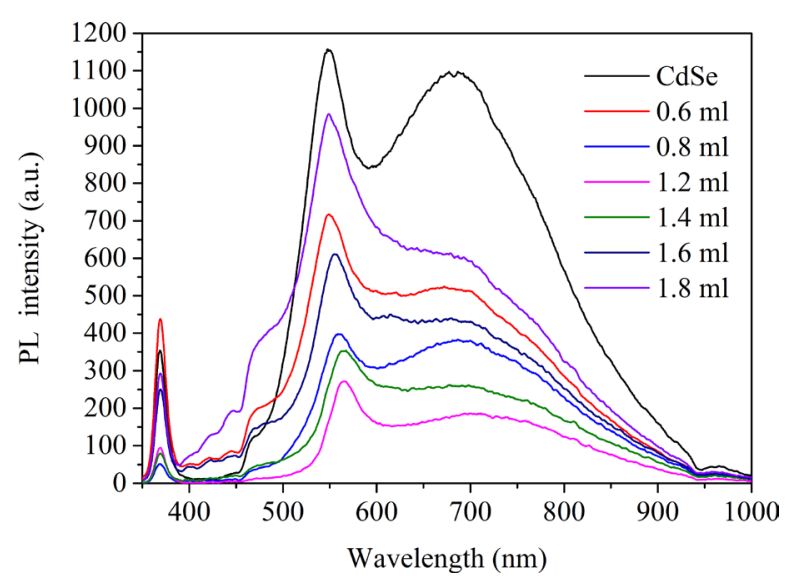

Fig. 1. (Color online) Photoluminescence spectra of $\mathrm{CdSe}$ and $\mathrm{CdSe/RGO-GO}$ prepared by using different amounts of RGO.

\subsubsection{Degradation experiment}

$150 \mathrm{~mL}$ of $\mathrm{RhB}$ solution with a concentration of $5 \times 10^{-5} \mathrm{~mol} / \mathrm{L}$ was put into a beaker. $80 \mathrm{~mL}$ of the $\mathrm{CdSe} / \mathrm{RGO}-\mathrm{GO}$ photocatalysts solution with a concentration of $1.19 \times 10^{-5} \mathrm{~mol} / \mathrm{L}$ was put into the same beaker. And then, the mixture was magnetically stirred at a constant temperature of $26^{\circ} \mathrm{C}$ to achieve degradation through the experiment. Meanwhile, the mixture was stirred for 10 minutes under no light irradiation, and was stirred for degradation from 10 to $60 \mathrm{~min}$ under visible light irradiation. $10 \mathrm{~mL}$ of the samples were extracted at regular intervals of $10,20,30$, 40, 50, and $60 \mathrm{~min}$, respectively. Each extracted solution from the degradation solution was centrifuged under $5000 \mathrm{rpm}$ for $5 \mathrm{~min}$ to remove the upper oil suspension every time. Then, the absorption of the aqueous solution was characterized by the UV-vis absorption spectrometer. The concentration of the solution was calculated from the intensity of the absorption spectrum. The degradation efficiency of the dye solution was calculated from the concentration evolution of the dye solution as a function of the degradation time.

\subsubsection{Recyclability test}

The oil phase CdSe/RGO-GO solution is easily separated from the Rhodamine aqueous solution due to their insolubility in water. After separation, it was washed three times with deionized water, and then the aqueous solution is drawn off and dried. In order to facilitate the preservation and reuse, the obtained aqueous solution can be prepared to be powder as following method. The prepared CdSe/RGO-GO solution was washed three times with a mixed solution of methanol and acetone at a ratio of $3: 1$, and then dispersed in a mixed solution of $\mathrm{n}$-hexane and absolute ethanol at a ratio of 1:5, sealed and put into a refrigerator for 8 hours. It was taken out until the powder precipitates out, then was filtered with Whatman filter paper $(0.7 \mu \mathrm{m}$ pore size, $47 \mathrm{~mm}$ diameter). Then it is dried at $70^{\circ} \mathrm{C}$ in a vacuum oven for 24 hours until it forms the CdSe/RGO-GO composites powder. After this the cleaned CdSe/RGO-GO composites were reused for removing dyes, and the circle experiment was repeated several times. 


\section{Results and discussion}

\subsection{Optical characterization of CdSe/RGO-GO}

The absorption spectrum of CdSe/RGO-GO photocatalyst shows the absorption peak of CdSe quantum dots at the wavelength of $502 \mathrm{~nm}$, which is the same as that of pure CdSe quantum dots (in Fig. 2). That indicates CdSe quantum dots are successfully produced. No new peaks appear in the composites, indicating that there is no obvious electronic interaction between CdSe quantum dots and graphene. Also, the adhesion of CdSe quantum dots on RGO nanosheets does not destroy the ordered structure of graphene. The defects location generated during the reduction process of GO become traps of electrons, which extends the carrier lifetime and improves the photocatalytic activity. Furthermore, the unreduced GO has a strong adsorption ability, and the CdSe/RGO heterojunctions have the ability to inhibit the recombination of photogenerated electrons and holes. Therefore, the photocatalytic activity and quantum efficiency can be improved under the synergistic effect.

TEM result shows that The CdSe nanoparticles were scattered on the RGO sheets (Fig. 3 a). A distinct contrast between the CdSe nanoparticles and the RGO nanosheets can be observed. The contrast of the upper left area is dark, while the adjacent areas at the bottom are bright. In the bright field image, under the same thickness, if there is a phase composed of heavy atoms in the region, the transmission electron beam is difficult to penetrate the area, shown as a dark contrast in the image. On the contrary, the region shows a bright contrast in the image when the phase composed of light atoms in the region. Combined with the analysis of the previous energy spectrum, it can be concluded that the phase in the dark contrast region is CdSe and the bright area is RGO nanosheets. To further confirm the above conclusion, the high resolution transmission electron microscopy (HRTEM) was used to analyze the phase of the interface. Fig. $3 \mathrm{~b}$ is an HRTEM photograph at the boundary of the light and the dark area shown in Fig. 3 a. Overall, the atomic arrangement in the region is random. We can see that the upper part of the image shows a certain ordered structure. In contrast, the atoms in the lower part marked by the dotted line are completely disordered. The Fourier transform (FFT) results in region A shows that the interplanar distance is 0.329 and $0.351 \mathrm{~nm}$,

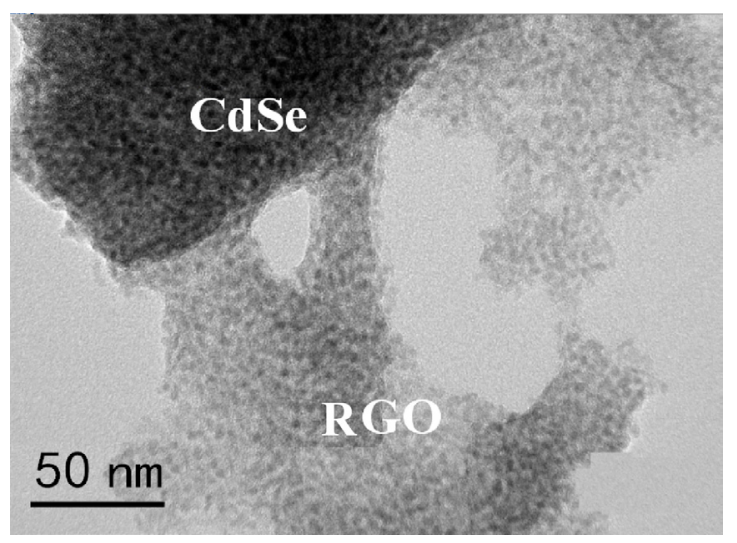

a

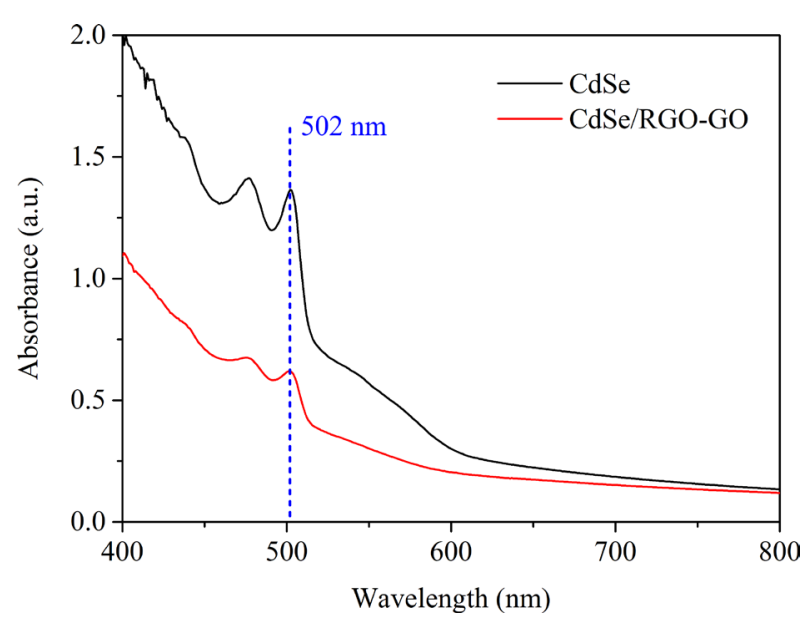

Fig. 2. (Color online) UV-vis spectra of the CdSe and CdSe/RGO-GO nanometer heterojunctions.

corresponding to the crystal plane distance of $\left(\begin{array}{lll}1 & 0-1 & 1\end{array}\right)$ and

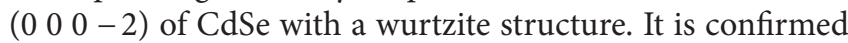
that the phase of the crystalline region is CdSe. The lattice fringes are corresponding to the $\left(\begin{array}{llll}0 & 0 & 0 & 2\end{array}\right)$ surface of the CdSe in the structure of six square crystal wurtzite from the region $\mathrm{B}$ shown in Fig. 3 b. Therefore, it can be inferred that the phase of the upper crystalline region A in Fig. $3 \mathrm{~b}$ is CdSe. In contrast, the phase in the lower crystalline region is RGO sheets.

\subsection{Adsorption and photocatalytic degradation of $R h B$}

It can be observed from Fig. 4 that the adsorption and degradation process of the $\mathrm{RhB}$ solution is related to the light radiation conditions and duration. The absorbance of $\mathrm{RhB}$ solution is about 0.95 at the beginning, while rapidly reduce to be about 0.15 under no light irradiation for 10 minutes during magnetic stirring with CdSe/RGO-GO photocatalysts, which is better than the previously prepared $\mathrm{CdSe} / \mathrm{RGO}$ catalysts at the report [17]. In addition, the degradation degree of Rhodamine solution under different light conditions and time intervals can be obtained. With the increase of degradation time, the degradation concentration of Rhodamine solution gradually decreased. After the whole degradation process, the intensity of the ultraviolet absorption spectra of the solution reaches about 0.06 .

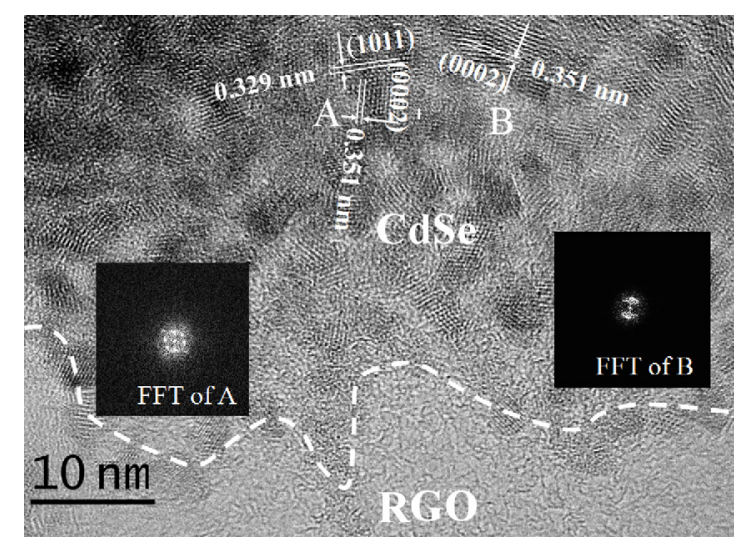

$\mathrm{b}$

Fig. 3. BFTEM (a) and HRTEM (b) images of the CdSe/RGO-GO nanometer heterojunctions. 
The calculation of photocatalytic reduction efficiency results shows that the concentration of $\mathrm{RhB}$ solution decrease by $4.2 \times 10^{-5} \mathrm{~mol} / \mathrm{L}$ in 10 minutes and the degradation efficiency is $94 \%$ in 60 minutes, which is much better than earlier reports $[17-20]$.

The mechanism of the CdSe/RGO photocatalysts is shown in Fig. 5. The narrow band gap of CdSe nanoparticles enables the electron-hole pairs generated even under visible light irradiation. These electron-hole pairs are prone to be separated by GO, which results in the formation of active electrons and holes. Electrons can be transported by RGO, which leaves active holes or participates in the photocatalytic reactions. Meanwhile, CdSe is a semiconductor with a narrow band gap, a number of electrons $\left(\mathrm{e}^{-}\right)$and holes $\left(\mathrm{h}^{+}\right)$ can be produced in CdSe even under no light irradiation. CdSe produces a self-degradation property, which leads to the degradation of RhB. And RGO nanosheets transfer electrons $\left(\mathrm{e}^{-}\right)$to the conduction band of CdSe, which increases the number of electrons as well as the rate of electron-induced redox reactions $[17,18,21]$. The positive charge hole $\left(\mathrm{h}^{+}\right)$can react with $\mathrm{OH}^{-}$derived from $\mathrm{H}_{2} \mathrm{O}$ to form hydroxyl radicals $\left(\mathrm{OH}^{\bullet}\right)$. The generated electrons $\left(\mathrm{e}^{-}\right)$react with dissolved oxygen molecules and produce superoxide radical $\left(\mathrm{O}_{2}^{--}\right)$. At the same time, Rhodamine adsorbed on the surface of the catalysts is easier to be catalyzed, which increases the concentration of reaction substrate in the catalysts. That can accelerate the interaction between reaction substrate and photo-generated species such as the electron,

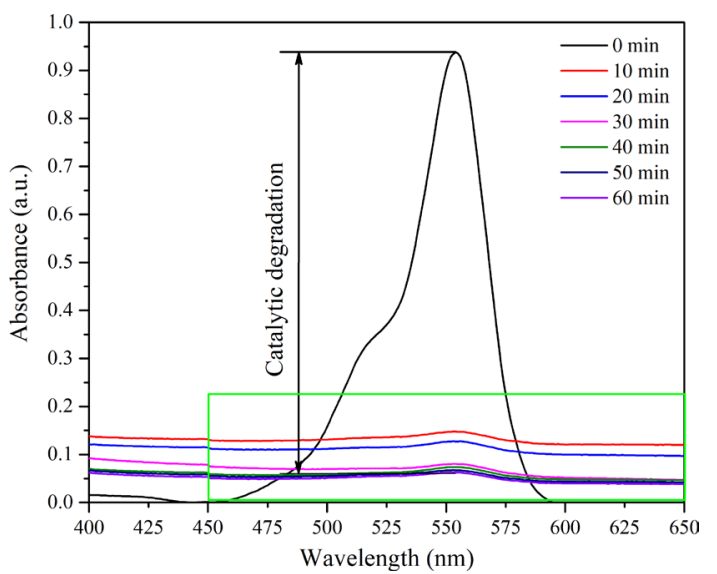

a

Fig. 4. (Color online) UV-Vis absorption spectra of RhB after being photocatalytically decomposed using the CdSe/RGO-GO nanometer heterojunctions at different time intervals (a). Magnified observation in the marked rectangle region of Fig. $4 \mathrm{a}$ (b).

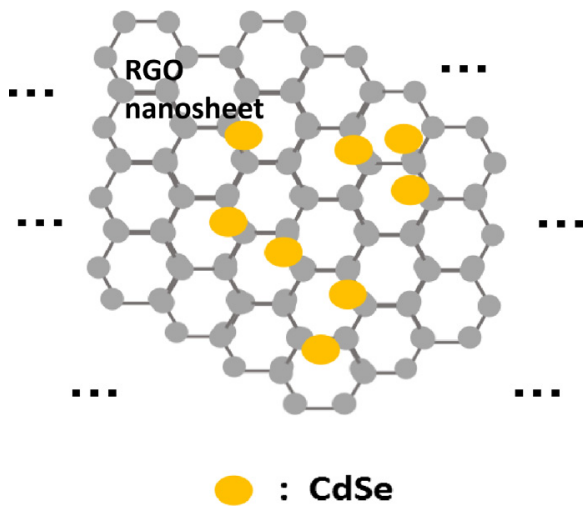

a

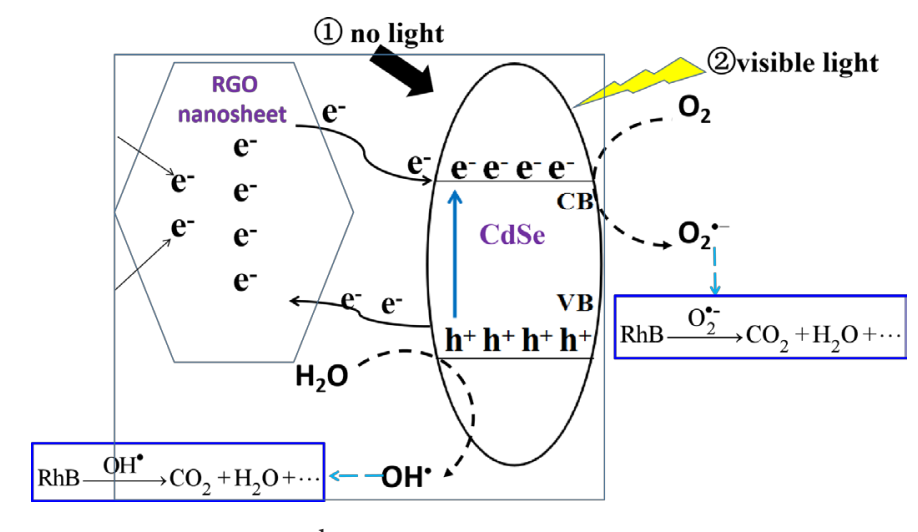

b

Fig. 5. (Color online) Schematic structure of the CdSe/RGO-GO photocatalysts (a). Photocatalytic degradation process (b). 
Acknowledgments. This work was supported by the projects of the National Natural Science Foundation of China (No. 61865002), Central Guide to Local Science and Technology Development (No. QKZYD[2018]4009), Anhui province higher education promotion plan (No. TSKJ2017B30).

\section{References}

1. Y. Landkocz, F. Ledoux, V. Andr, F. Cazier, P. Genevray, D. Dewaele, P. J. Martin, C. Lepers, A. Verdin, L. Courcot, S. Boushina, F. Sichel, M. Gualtieri, P. Shirali, D. Courcot, S. Billet. Environmental pollution. 221, 130 (2017). Crossref

2. M. Tobler, Z.W. Culumber. Science. 354, 1232 (2016). Crossref

3. R. Asahi, T. Morikawa, T. Ohwaki, K. Aoki, Y. Taga. Science. 293, 269 (2001). Crossref

4. D. H. Cui, Y.F. Zheng, X.C. Song. Journal of Alloys and Compounds. 701, 163 (2017). Crossref

5. S. K. Mohapatra, N. Kondamudi, S. Banerjee, M. Misra. Langmuir. 24 (19), 11276 (2008). Crossref

6. W. Zhu, F. Sun, R. Goei, Y. Zhou. Applied Catalysis B: Environmental. 207, 93 (2017). Crossref

7. H. Tong, O. Shuxin, B. Yingpu, U. Naoto, O. Mitsutake, Y. Jinhua. Advanced materials. 24, 229 (2012). Crossref

8. W. Xiaofeng, P. Jiaqi, W. Song, M. Jie, Z. Yingying, C. Can, L. Chaorong. Journal of Materials Science: Materials in Electronics. 28, 14079 (2017). $\underline{\text { Crossref }}$
9. S. Gayathri, P. Jayabal, M. Kottaisamy, V. Ramakrishnan. Journal of Applied Physics. 115, 173504 (2014). Crossref

10. Y.H. Ding, P. Zhang, Q. Zhuo, H. M. Ren, Z. M. Yang, Y. Jiang. Nanotechnology. 22, 215601 (2011). Crossref

11. S. Chu, W. Li, Y. Yan, T. Hamann, I. Shih, D. Wang, Z. Mi. Nano Futures. 1, 022001 (2017). $\underline{\text { Crossref }}$

12. J. M. Carlsson. Nature Materials. 6, 801 (2007). Crossref

13. A. Fasolino, J.H. Los, M. I. Katsnelson. Nature materials. 6, 858 (2007). Crossref

14. S. Pei, H. M. Cheng. Carbon. 50, 3210 (2012). $\underline{\text { Crossref }}$

15. H. Zhang, X. Lv, Y. Li, Y. Wang, J.Li. ACS Nano. 4, 380 (2009). Crossref

16. L. Xiao, Y. Wang, S. Yu, Y. Tang. Progress in Chemistry. 25 (2), 419-430. Z1 (2013).

17. T. Ghosh, J. Lee, Z. Meng, K. Ullah, C. Park, V. Nikam, W.Oh. Materials Research Bulletin. 48, 1268 (2013). Crossref

18. K. Ullah, J. Sun-Bok, S. Ye, L. Zhu, G. Mukhopadhyay, W.C. Oh. Fullerenes, Nanotubes and Carbon Nanostructures. 23, 437 (2015). Crossref

19. W. Oh, M. Chen, K. Cho, C. Im, Z. Meng, L. Zhu. Chinese Journal of Catalysis. 32, 1577 (2011). Crossref

20. M. Zhou, J. Li, Z. Ye, C. Ma, H. Wang, P.Huo, W. Shi, Y.Yan. ACS applied materials \& interfaces. 7, 28231 (2015). Crossref

21. N. Thirugnanam, H. Song, Y.Wu. Chinese Journal of Catalysis. 38, 2150 (2017). $\underline{\text { Crossref }}$ 